\title{
Vidas Medicalizadas: por uma Genealogia das Resistências à Farmacologização
}

Medicalized Lives: for a Genealogy of Resistances to Pharmaceuticalization

Vidas Medicalizadas: por una Genealogía de las Resistencias a la Farmacologización
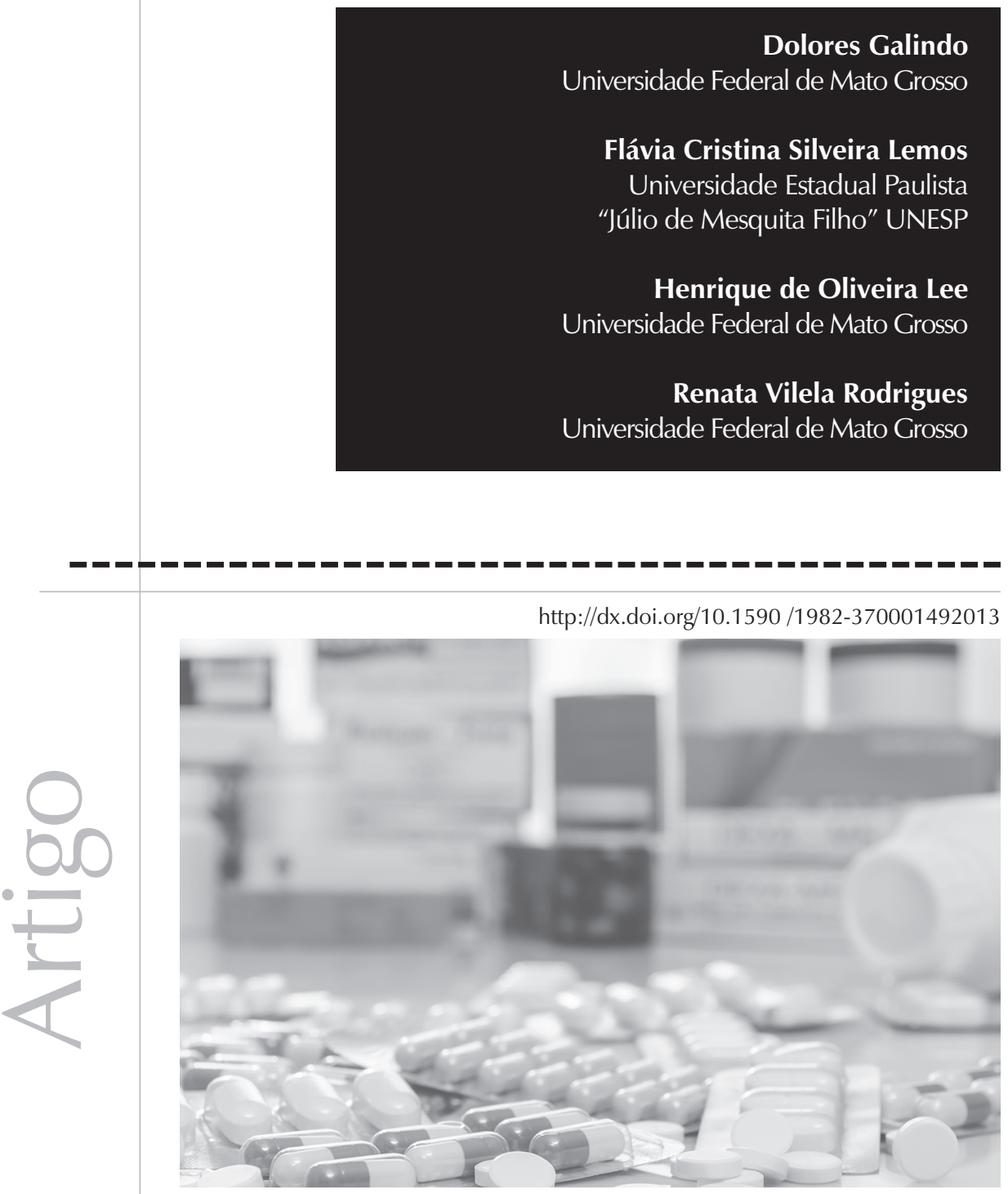
Resumo: Este artigo visa a colocar em debate, em formato de ensaio teórico, a temática da medicalização e da farmacologização da existência. Discute-se a multiplicidade de acontecimentos que sustentam a medicalização e o campo de lutas no qual tais situações ocorrem e se materializam em um dispositivo de farmacologização subjetivante. Recupera-se, para tanto, aspectos da obra de Rodrigo Souza Leão que problematizam dimensões dos modos de subjetivação atuais urdidos na economia política da indústria farmacêutica e que instauram práticas de liberdade. Ao final do artigo, conclui-se que a difusão da medicalização e da farmacologização da vida é uma prática muito disseminada e, portanto, as resistências endereçadas às mesmas precisam ser ampliadas e articuladas cada vez mais com vistas a produzir efeitos na sociedade atual, de maneira a abrir brechas que façam ressoar práticas não medicalizantes em um campo de tensão de forças. Propomos que a genealogia das resistências à medicalização das existências deve ser articulada à composição de arquivos não conformistas capazes de evidenciar que, apesar da força da farmacologização na configuração das nossas subjetivações, práticas de liberdade continuam a ser urdidas em seus interstícios.

Palavras-chave: Medicalização. Farmacologização. Resistências. Escrita.

Abstract: This paper aims at setting into discussion, in a theoretical essay format, the topic of medicalization and pharmaceuticalization of existence. It discusses the multiplicity of events that support medicalization and the field of struggles in which such situations take place and are materialized into a subjectivizing pharmaceuticalization device. Thus, some features of Rodrigo Souza Leão's work are retrieved which argue on the dimensions of current subjectivizing manners hatched out in the pharmaceutical industry economic policy and that set freedom practices. One concludes, by the end of the paper, that diffusion of medicalization and pharmaceuticalization of life is a widespread practice and, therefore, resistances targeting them need to be increasingly expanded and articulated aiming at producing effects in current society to open gaps that reverberate non medicalizing practices in a tension field of forces. We propose that genealogy of resistances to medicalization of existences should be articulated with the composition of non-conformist files capable of evidencing that, in spite of the pharmaceuticalization power in setting up our subjectifications, freedom practices continue to be plotted in their interstices.

Keywords: Medicalization. Pharmaceuticalization. Resistances. Writing.

Resumen: Este artículo visa colocar en debate, en formato de ensayo teórico, la temática de la medicalización y de la farmacologización de la existencia. Se discute la multiplicidad de acontecimientos que sustentan la medicalización y el campo de luchas en el cual tales situaciones ocurren y se materializan en un dispositivo de farmacologización subjetivante. Se recuperan, para tanto, aspectos de la obra de Rodrigo Souza Leão que problematizan dimensiones de los modos de subjetivación actuales urdidos en la economía política de la industria farmacéutica y que instauran prácticas de libertad. Al final del artículo, se concluye que la difusión de la medicalización y de la farmacologización de la vida es una práctica muy diseminada y, por tanto, las resistencias dirigidas a las mismas precisan ser ampliadas y articuladas cada vez más con vistas a producir efectos en la sociedad actual de manera a abrir brechas que hagan resonar prácticas no medicalizantes en un campo de tensión de fuerzas. Proponemos que la genealogía de las resistencias a la medicalización de las existencias debe ser articulada a la composición de archivos 
no conformistas capaces de evidenciar que, a pesar de la fuerza de la farmacologización en la configuración de nuestras subjetivaciones, prácticas de libertad continúan siendo urdidas en sus intersticios.

Palabras-clave: Medicalización. Farmacologización. Resistencias. Escrita.

Este artigo visa trazer uma problematização dos processos de medicalização a partir de uma analítica foucaultiana, colocando em xeque a farmacologização das existências como um campo de lutas, na sociedade contemporânea. Por meio da escrita, e inserindo-se nas linhas que formam os procedimentos de saber-poder da medicalização, o texto em pauta opera a crítica a estes e aponta para a literatura, em especial, para a obra de Rodrigo Souza Leão, como um operador de rupturas - pequenos desvios - no dispositivo de farmacologização da vida que restringe práticas de liberdade.

A partir do legado deixado por Foucault (1999a, 1999b), sabe-se que a analítica dos acontecimentos como genealogia é uma maneira de fazer traçar as relações de força, as disputas e a multiplicidade de práticas heterogêneas em jogo. Não há uma raiz ou tronco comum a encontrar como origem de algo e também não há o fim da lança, como apogeu de um desenrolar de fatos, contínuos e encadeados causalmente, ou seja, sem teleologia e fins a decifrar. Em decorrência, a genealogia das práticas de resistência à farmacologização das existências passa por uma analítica dos mecanismos e estratégias normalizadoras de governo e disciplinarização dos corpos, bem como dos mecanismos e forças contemporâneas constituídas pelas ciências modernas que concorrem para a expansão da medicalização expressa em um crescente consumo de fármacos no Brasil, sendo este o primeiro movimento conceitual e político do presente texto.

Entendendo que as práticas de resistência à homogeneização dos modos de subjetivação emergem nas tramas que engendram o dispositivo de farmacologização e não do seu exterior, o segundo movimento deste texto consiste em evidenciar, sem pretensão de exaustividade, algumas linhas de fuga ao dispositivo medicalizante que se fazem presentes na obra de Rodrigo Souza Leão, escritor cuja biografia foi marcada por internações, eletrochoques e ingestão de altas doses de psicotrópicos prescritos. Diagnosticado como esquizofrênico, Rodrigo Souza Leão resistiu ativamente ao enquadramento do seu trabalho como expressão de uma patologia e manteve uma intensa participação na vida literária brasileira. Do seu apartamento, de onde quase nunca saía, condição que o incomodava conforme é relatado em sua página pessoal, colaborava com revistas digitais, telefonava para outros escritores, mantinha uma página eletrônica e lançava livros, vários deles em edições virtuais. As internações, o diagnóstico, os medicamentos foram integrados à escrita do autor como matéria poética e esta é trazida ao plano do nosso texto como expressão de uma prática de liberdade que o controle por ondulações químicas não logrou homogeneizar.

A questão sobre a produção de liberdades se coloca não apenas para o processo de farmacologização, mas, antes, para o estabelecimento de uma formação hegemônica, uma vasta rede de articulação de elementos que se condicionam e se legitimam mutuamente. Uma rede que estabelece uma cumplicidade tácita entre certa visão da doença mental, certo modo de produção e uma visão do que seja a ordem pública. A obra de Rodrigo Souza Leão, aparentemente solitária e desengajada das grandes lutas coletivas 
ligadas diretamente às políticas de saúde mental, constitui uma escrita de resistência e de cumplicidade que é possível apenas aos desviantes, aos infames, aos "sujeitados".

\section{A Indústria farmacêutica e o campo de lutas político- econômicas em rede com as relações disciplinares de poder}

A concentração de capital das indústrias farmacêuticas e a expansão dos diagnósticos de síndromes em saúde vêm ampliando exponencialmente o número de enquadramentos diagnósticos e de processos de medicalização dos mínimos desvios sociais frente às normas. De acordo com o Boletim de Farmacoepidemiologia da Agência de Vigilância Sanitária (Anvisa), publicado no segundo semestre de 2011, 44\% dos remédios vendidos nas farmácias e drogarias são para o objetivo de, supostamente, tratar os quadros produzidos como transtornos mentais e de comportamento. A pesquisa aponta que, em 2010, foram vendidas cerca de 10 milhões de caixas do medicamento Clonazepan, o que representou um gasto em torno de $\mathrm{R} \$$ 92,4 milhões apenas com esse medicamento, entre os brasileiros (Anvisa, 2011). Esse consumo exacerbado de psicofármacos é um indicativo não apenas de uma tendência global de aumento dos gastos com medicamentos, mas também um analisador da importância que as substâncias psicoativas adquiriram nas sociedades contemporâneas.

Foucault (1979) nos deixou relevante legado, ao assinalar que a produção e a incitação das relações de poder, como exercício e dinâmica de forças móveis, forjam saber e engendram corpos saudáveis, ágeis, capazes, normalizados, obedientes politicamente, adestrados para o trabalho e para a educação disciplinar. Corpos úteis e dóceis são efeitos de procedimentos de controle por práticas disciplinares que visam a formar alinhamentos políticos como obediência e assujeitamento acrítico. Corpos vigiados e punidos integram uma sociedade da vigilância, panóptica e que opera por alinhamento político.

O poder disciplinar se generaliza a partir do século XVII, como prática de controle meticuloso dos corpos para torná-los úteis e dóceis, produtivos e governados por mecanismos de vigilância, de gestão do tempo e do espaço, pela sanção normalizadora e pelo exame. Simultaneamente à emergência da Revolução Francesa e do aparecimento das Luzes, apareceram as disciplinas, ou seja, liberdade e disciplina nasceram juntas e balizam uma e outra, no campo da política como guerra prolongada por outros meios (Foucault, 1999a).

Depois de quinze anos da chamada Reforma Psiquiátrica brasileira e dos efeitos de outras tantas transformações, nos cenários de promoção e cuidado em saúde, os usuários encontram nas consideradas novas modalidades de tratamentos em serviços substitutivos uma diversidade de caminhos para a sua reinserção na comunidade e para a convivência social em meio aberto (Bezerra, 2009). São formas sutis de governo dos corpos e da vida, que tendem a ganhar mais evidência do que a modalidade de segregação da disciplina bloqueio do corpo. Discordar se tornou sintoma de um transtorno, aprender em ritmos diferenciados ou ainda estar desatento e questionar grupos passou a ser considerado sinal de anormalidade, com explicações da história de vida de cada um, ou seja, liberalismo como racionalidade política e como estilo de vida.

As mutações trazidas pelos movimentos de Luta Antimanicomial, de Reforma Psiquiátrica, de interrogação das normas fixas e supostamente naturais de viver, das relações de gênero e de configuração familiar, acrescidas da ampliação e reconfiguração das práticas 
clínicas e da oferta de uma rede pública e privada de atendimentos psicológicos e médicos, abriram novas possibilidades de estabelecimento de laços para os usuários de saúde mental e seus familiares (Castel, 1987). Ao mesmo tempo, a cooptação das forças de luta como mercadoria e como instrumental a ser consumido - contudo, esvaziado da política - tem sido uma prática muito comum.

Foucault (1999a) assinala os usos do tempo como mecanismo disciplinar e a objetivação dos corpos pela velocidade na política e no cálculo econômico. O tempo como economia política e o controle da resistência operam pelo regramento da vida no relógio e na capitalização dos segundos e dos resultados que obtemos neles, em termos de utilidade e de docilidade política. O ritmo de resposta deve estar na rapidez e lentidão necessárias para que os que usurpam o tempo de luta possam usá-lo como mercadoria a ser comercializada e trocada como moeda de favor, em jogos de interesse.

Em políticas mais atuais de saúde mental, a dispensação de psicofármacos vem sendo, frequentemente, utilizada para amenizar o denominado sofrimento psíquico, visando a produzir sujeitos dóceis e úteis. A farmacologia dispõe do corpo como objeto e alvo de poder a ser domesticado e adestrado, ao qual se pode modelar por treinos e tentar fazer obedecer e responder aos estímulos e exercícios, com vistas a torná-lo hábil para multiplicar-lhe as forças. Para uma variedade de especialistas, os tratamentos medicamentosos podem melhorar ou estabilizar performances variadas e promover apropriações de oportunidades com certa regularidade disciplinar e biopolítica, ou seja, com controle da minúcia e da totalidade dos atos do corpo e da vida, concomitantemente, em espaços abertos e fechados ou, sobretudo, no fluxo entre ambos, conforme demandado pelas sociedades de controle. As táticas disciplinares de vigilância e controle em meio aberto são mais rentáveis que as do controle fechado, sendo a farmacologização um dos vetores que aceleram o controle biomédico a distância: o medicamento é subjetivante e não apenas um conjunto de propriedades químicas delimitáveis.

Os medicamentos agem conformando modos de ser e instaurando certa sensação de normalidade medicalizada, na qual a expressão do sofrimento (de qualquer origem e forma) não se torna objeto de reflexão ou busca de construção de outras formas de ser, mas de um "bloqueio químico" das emoções, que pode ser combinado com técnicas disciplinares da clínica psiquiátrica e psicológica articuladas à medicalização, no campo das tecnologias de gestão de riscos, segundo evidenciam os estudos de Castel (1987) a respeito da psicologização da sociedade. Os psicofármacos passaram a definir as condições de saúde e, em alguns casos, silenciá-las com uma somatória de técnicas de normalização das condutas. É nesse sentido que a intervenção farmacológica como tecnologia de controle procura limitar, modificar, regular, isolar e eliminar comportamentos desviantes, por meio dos recursos biotecnológicos e em nome de uma saúde normalizada (Brzozowski \& Caponi, 2010).

Com a primazia da medicalização do sofrimento, fluoxetinas, sertralinas, diazepams, alprazolams se tornam uma espécie de magia, com rituais estranhamente milagrosos que "tratam" os sofrimentos psíquicos (Ignácio \& Nardi, 2007). Os sofrimentos são objetivados como psíquicos e bioquímicos, ao mesmo tempo, quando não apenas genéticos, comportamentais, hormonais e de desníveis de neurotransmissores. Assim, são individualizados e pensados como tendências sintomáticas. Na perspectiva da modulação neuroquímica, a vida e os corpos estão sendo 
amplamente farmacologizados, produzindo indivíduos que demandam a medicação como terapêutica associada às técnicas de controle disciplinar, em geral, de aprendizagem comportamental. Em Os anormais, Foucault (2002) ressalta que a biografia dos desviantes e dos chamados indivíduos de sucesso passou a ser usada para realização de um controle normalizador dos corpos, em que qualquer afastamento de modelos idealizados como normais se tornou enquadrado em psicodiagnósticos médico-psicológicos produtores de carimbos de doença e medicalização da subversão política.

A Medicina, desde o século XIX, penetrou na sociedade atuando na constituição de um olhar que produz a doença como transtorno, articuladamente ao campo das decisões políticas de saúde, baseadas em um intenso processo de medicalização. Foucault (1979) sublinhou que a Medicina Social foi se tornando mais higienista do que terapêutica, porque tem objetivado mais organizar e fazer funcionar a ordem social do que cuidar de alguém que apresenta um mal-estar e demanda um espaço de problematização de si. Nos seus desenvolvimentos contemporâneos, ao controle social médico é adicionado o consumismo dos dispositivos farmacológicos.

Foucault (1979) já apontava que a inserção do Estado no campo da Saúde socializou não só a Medicina, como também o corpo, que passa a ser visto como uma realidade biopolítica. Saúde e Medicina transformaram-se em estratégias de economia, gastos são destinados a uma série de medidas sanitárias. Ainda que a promoção de saúde seja alvo central do Estado, não se trata das consequências da falta de saúde, mas dos custos relacionados à saúde-doença. Acompanhamos a ampliação do que Foucault (1979) nomeou de higiene da cidade e dos trabalhadores, na sociedade, em uma combinação de práticas vizinhas de governamentalidade do Estado pelos mecanismos pastorais igual- mente designados de salvação da saúde como valor de mercado e de disputa liberal, em um capitalismo neoliberal de concorrência (Foucault, 2008).

O autor antevia que a Medicina aumentaria seu prestígio na aliança com os Estados Modernos, mas que não ficaria reduzida a ele como racionalidade governamental, conforme acompanhamos na mobilização das empresas farmacêuticas como tecnologias de medicalização, o que traz consigo uma forte presença das pressões mercadológicas e a colocação em cena de formas de subjetivação pautadas por princípios ativos das substâncias prescritas. Os dispositivos de farmacologização operam nos corpos como estratégias de controle legitimadas política e socialmente, por estarem acopladas aos modos de subjetivação (Ignácio \& Nardi, 2007; Lopes, 2004).

Foucault (2004), ao tratar da ordem do discurso, salienta que uma disciplina e seu objeto, suas técnicas e seus conceitos, lugares institucionais, sistemas de difusão e sociedades formam um dispositivo de poder e de saber. Alerta seus leitores a respeito de que o dispositivo é um efeito de forças heterogêneas as quais constituem uma ordem do discurso, e que este é um efeito de paradoxo, já que o princípio arqueológico da dispersão, da rarefação, da desdisciplinarização dos saberes e da insurreição dos saberes, na genealogia, põe em xeque a suposta unidade que muitos desejam atribuir a um campo de práticas. O status de fala e do lugar de poder em que se fala e em que se prescreve com legitimidade está ligado a um conjunto de práticas relacionadas e distintas, que foram arbitrariamente interligadas. Tais procedimentos não são naturais e, no caso da Medicina, estão vinculados aos agentes institucionais e técnicos, aos temas e lugares em que se autoriza alguém a falar de e a indicar práticas, aos mecanismos de controle social dos meios médicos tecnológicos, especialmente dos medicamentos e das cirurgias. 
Atentando para a crescente expansão da medicalização na vida das pessoas, por meio da inserção na prática e nos discursos cotidianos sobre fármacos, Lopes (2004) explicita que, paralelamente à medicalização, desenvolve-se atualmente o processo de farmacologização em consequência da crescente expansão da medicalização na vida das pessoas. Farmacologização é um acontecimento em que os medicamentos são dominantes nas opções terapêuticas, ou seja, a gestão do corpo e da saúde tornou-se problema farmacológico e não mais médico. Expectativas de cura e/ou alívio recaem sobre os medicamentos. Para Lopes (2007), o recurso aos fármacos constitui a primeira opção das pessoas na gestão da vida e das problemáticas que são fabricadas no decorrer do lidar cotidiano com os inesperados, trágicos e frustrações que possam ocorrer.

Assim, silencia-se uma série de demandas em jogo por meio da medicalização e da farmacologização da existência. Os efeitos de iatrogenia são diversos, inúmeros problemas colaterais advindos do uso indiscriminado dos medicamentos e da lógica que os sustenta. Desse modo, é fundamental criar redes de resistência e de crítica política a essas práticas.

Nosopolítica, biopolítica

e gestão da vida na medicalização e na farmacologização das existências

Está em jogo uma nosopolítica, como nos indicou Foucault (1979), em concomitância com a polícia disciplinar das condutas administradas pelos saberes e poderes da norma e do exame, que nos recomendam prescrições de bem-estar, em todo um amplo espectro de incitações de um suposto viver saudável, produtivo, dócil e de disposição, a extrair cada vez mais potência do corpo e de suas capacidades. O surgimento do Prozac ${ }^{\circledR}$
(Fluoxetina), em 1988, desencadeou maior interesse e respeito sobre os psicofármacos e os considerados bons resultados em seu uso no tratamento de supostas doenças mentais. Outros fármacos apareceram e mais pesquisas fortaleceram a ideia de que os transtornos psíquicos são doenças com etiologia biológica, explicadas por alterações químicas e tratadas quimicamente (Bogochvol, 1995 citado por Perecy \& Oliveira, 2010). A instrumentalização da psicofarmacologia como tratamento foi promovida sob a égide da Psiquiatria estadunidense, particularmente pela popularização das últimas edições dos Diagnostic and Statistical Manual of Mental Disorders (DSM) e da International Classification of Diseases (CID). Nesses manuais que regem a prática clínica, o sintoma é a própria doença ou, mais propriamente, o chamado transtorno mental, apoiando-se em um substrato supostamente evidente e inquestionável.

Produz-se um jogo de capturas nas prescrições dos manuais médicos, nutricionais, psicológicos e educativos direcionados a melhorar a saúde e mantê-la, aumentar a longevidade e não adoecer, continuar vigorosos e jovens. Ora, Foucault (2008) enfatiza que o mercado da vida se baseia na construção desta como um valor a ampliar e a zelar, a gerir e a intensificar politicamente por um conjunto de governamentalidades e pastorais administrativas, médicas, psicológicas, pedagógicas, demográficas, estatísticas, geográficas, econômicas, sociais e culturais. $\mathrm{O}$ mesmo se estende à produção de uma suposta necessidade de articulação de vários saberes, visando a formar uma rede de cuidado densa, diversificada e dita efetiva na oferta, promoção e tratamento em saúde (Staub \& Hoch, 2012).

Ao analisar o neoliberalismo, Foucault (2008) aponta como a sociedade civil e Estado estão interligados e formam composições múltiplas, híbridas - racionalidades que resultam de 
jogos permanentes e que não configuram entidades unitárias. No âmbito das governamentalidades neoliberais, a preconização do tratamento farmacológico é uma das consequências da privatização do sofrimento, do seu emudecimento, da sua transformação em um conjunto de sintomas que implica em prescrições de tratamentos bioquímicos, psicológicos os mais variados, de exercícios físicos e relacionais, de dietas e estéticas corporais normalizantes, em um intenso mercado da saúde.

É um mercado que se apoia na defesa de que o sofrimento e a dor provocam prejuízos e diminuem os prazeres, impedem oportunidades, forjam danos e custam caro para o indivíduo, para sua família, para a sociedade e para o Estado, em termos econômicos, sociais e securitários. São farmacologizadas incessantemente novas esferas da vida e segmentos da população, tendo em vista a manutenção da ordem entre as pessoas consideradas perigosas e o aumento da capacidade laboral ou cognitiva entre aquelas julgadas potencialmente úteis. Não se faz mais do que reproduzir sub-repticiamente uma definição tautológica, na qual doença mental é conceituada por força de sua transgressão da ordem pública hegemônica.

O entrecruzamento da Química e da Medicina, ciências que dão base à Farmacologia, ocorreu bem antes do surgimento desta última como campo de saber determinado, havendo emergido das preocupações com a qualidade do ar nas cidades (Foucault, 1977). Tal cumplicidade atinge seu grau máximo de determinação na noção de "evidência", constituindo hoje o fundamento do pragmatismo terapêutico. Por isso, as categorias com as quais definimos a doença mental, que aparenta ser positivamente conceituada por manuais, não fazem mais que reproduzir sub-repticiamente uma definição tautológica, na qual a doença mental é definida por força de sua transgressão da ordem pública hegemônica.

O dispositivo de farmacologização arrastado por uma noção de ciência baseada em "evidências" ocasiona um crescente esforço de classificação e catalogação das formas de vida e suas variações, por meio de referentes universais. Esses universais assumem uma conotação normativa no interior das práticas disciplinares e de governo e uma variação deixa de ser uma mera variação, para se tornar um déficit ou um exagero, em relação a um parâmetro implícito de normalidade. São universais que, configurados como síndromes e sintomas, permitem uma margem de imprecisão suficiente para que seja posta em ação a normalização traduzida nos diagnósticos diferenciais realizados sob o olhar da clínica psiquiátrica.

A noção de doença mental, que veio a substituir a imprecisa impressão da noção de loucura, data do século XIX, resultando da aliança entre a materialidade da doença/sintoma e da imaterialidade do domínio que passa a constituir a dimensão mental. Em A História da Loucura, acompanhamos como a doença mental obscurece e carrega consigo uma rede heterogênea de práticas de controle, forjando, também, um modo de subjetivação voltada ao espaço interior (Foucault, 1978). Ora, com a entrada em cena do dispositivo de farmacologização, há um esmaecimento do espaço interior, conduzindo a novas formas de subjetivação nas quais a química, o cérebro e as neurociências - impulsionados pelas empresas farmacêuticas - adquirem proeminência, criando selves neuroquímicos (Rose, 2007). 


\section{A escrita de Souza Leão, uma literatura de resistência à farmacologização}

Foucault (1970) constata que a escrita literária posicionada como saber não conceitual, sem qualificação, fragmentado e sem pretensão à verdade compõe um plano de experiência para resistências que em outras tramas não são possíveis. A experiência literária ao ser tolerada, ou simplesmente ignorada, pelas tramas de saber-poder medicalizantes, constitui um plano de experimentação e de resistências que materializa práticas de liberdade.

É no interstício entre a resistência tornada possível e sua não pretensão à verdade que a escrita literária de Rodrigo Souza Leão é capaz daquilo que poderíamos chamar de práticas de liberdade. Não se trata, obviamente, de uma liberdade desmedida e ilimitada, mas de uma transformação possível e sutil, uma pequena fuga ao discurso monolítico e aparentemente incontornável do poder psiquiátrico na medicalização das existências.

Nesse ponto, vale o alerta de Revel (2006) quanto à opção de Foucault, a partir da década de 1970, pela noção de resistência, ao invés de transgressão, para referir às práticas de liberdades que operam no interior das relações de poder que, também, delas se nutrem:

É preciso prestar atenção ao termo "transgressão", porque Foucault, que o toma provavelmente de Bataille no início dos anos 1960, o abandona rapidamente precisamente porque a relação entre o limite e a transgressão do limite parece fechar-se num círculo dialético. A partir dos anos 1970, Foucault fala em revanche de "resistência", ele afirma que a resistência, como prática da liberdade, se dá no próprio interior das relações de poder (e não fora do mesmo), e que, inversamente, as relações de poder se nutrem da liberdade das pessoas, ele consegue, apesar de tudo, quebrar a falsa simetria entre os dois termos. (Revel, 2006, pp. 22-23)

O escritor Rodrigo Souza Leão, nascido em 1965 no Rio de Janeiro, teve uma vida atravessada por internações psiquiátricas, eletrochoques, ingestão de fármacos administrados em altas doses e pelo isolamento durante longos períodos no interior do seu apartamento. Veio a falecer na última das suas internações, aos dois dias de julho de 2009, constando do atestado de óbito a morte por complicações cardíacas. Apesar das internações e dos longos períodos de isolamento, o artista manteve contato com outros escritores, colaborações em revistas eletrônicas, sendo um importante articulador cultural. Dedicou-se intensamente à atividade literária, publicando dez livros: 25 Tábuas; No Litoral do Tempo; Síndrome; Impressões sob Pressão Alta. Na Vesícula do Rock. Miragens Póstumas; Meu Primeiro Livro que é o Segundo; Uma temporada nas Têmporas; $O$ Bem e o Mal Divinos; Suorpicious Mind e Omar. Seus poemas foram publicados nas revistas Coyote, Et Cetera, Poesia Sempre, El Piez Naufrago, Oroboro. Manteve, ainda, um blog intitulado LowCura no qual, durante cerca de três anos, publicou textos literários entremeados à narração de incidentes cotidianos e familiares.

Entre diversos aspectos presentes na escrita de Rodrigo de Souza Leão, interessa-nos, para os fins da discussão proposta neste artigo, um recorte, certa parte de sua obra que tem em comum o fato de encenar uma dissolução do vocabulário técnico totalizante da medicalização psiquiátrica. O artista faz das marcas dos remédios que lhe são prescritos e dos estados que the provocam os tratamentos psiquiátricos invasivos, como os eletrochoques, uma força de resistência que tramada com ironia, dor e festividade produz modos de relação com os fármacos que recusam a ação subjetivante da medi- 
calização assentada na universalização da experiência sob a insígnia diagnóstica e a finalidade curativa da anestesia. Por isso, afirmamos que, mesmo ingerindo medicamentos, mesmo sofrendo eletrochoques, Rodrigo Souza Leão, por meio da escrita literária, opera pequenos desvios nas finalidades estratégicas do dispositivo de farmacologização das existências, desvios que podem ser imperceptíveis quando consideradas as alianças biopolíticas que o engendram.

Em Todos os cachorros são azuis, Rodrigo Souza Leão elabora uma narrativa híbrida de um paciente psiquiátrico que faz oscilar as vozes da narração de primeira para terceira pessoa, em que o narrador parece se dirigir ao seu duplo e a outras alteridades imaginárias, entre elas Rimbaud e Baudelaire. Em momento algum, o autor efetiva um pacto de leitura autobiográfico, nenhuma identidade entre Rodrigo e o narrador é afirmada, o leitor é apenas convidado a um jogo no qual o autobiográfico se deixa entrever por certas imagens que possuem ressonância na biografia do autor, como o delírio de ter engolido um chip. A narrativa de Todos os cachorros são azuis pode ser um fragmento de uma das internações de Rodrigo, mas pode ser também a narrativa de qualquer paciente psiquiátrico.

Nos poemas do livro Janelas Deitadas (síndrome), cuja temática central versa sobre as internações e os diferentes fármacos que ingere como tratamento para o diagnóstico de esquizofrenia, os nomes dos medicamentos deixam de ser marcas registradas das corporações farmacêuticas e se tornam nomes próprios, ícones de estados mentais, marcam carnavais, formam galáxias. São medicamentos, igualmente, mas não apenas. São armas poéticas de desobediência em um corpo atravessado por dispositivos que visam a controlar quimicamente, mas que redundam, em criação e, em certo sentido, também em testemu- nho da rotina das receitas, das prescrições das bulas, das diferenças sociais nas drogas que ingerimos:

$$
\begin{gathered}
\text { prozac lexotam tomava } \\
\text { isac piportil no haldol } \\
\text { risperdal para riquinho } \\
\text { gardenal para doido total } \\
\text { assim amplictil polenta } \\
\text { assim foi o meu carnaval } \\
\text { novalgina no pintinho } \\
\text { mertiolate corpo inteiro } \\
\text { pijama sem bolinhas } \\
\text { e um céu que poderia } \\
\text { esconder qualquer estrela } \\
\text { a bula dos alquimistas } \\
\text { os enfermeiros comemoram } \\
\text { injetando morfina em ratos } \\
\text { ratos que são sem ser cobaias } \\
\text { loucos sem camisa ao sol } \\
\text { sob o sol muito haldol } \\
\text { pipas no vento de haldoperidona } \\
\text { galáxias cheias de endorfina } \\
\text { dentro de mim toda a química } \\
\text { se vicia sem a si viciar. } \\
\text { (Leão, 2001, p. 44) }
\end{gathered}
$$

A escrita de Rodrigo Souza Leão traça uma resistência imprecisa e, quiçá, tão paradoxal como aquela que Foucault (1977) encontra nos peregrinos que vão a Lurdes à procura de milagres, uma resistência ao controle médico autoritário dos seus corpos e vidas - o sujeitado se insurge. No limite, é possível ler a obra de Leão como uma resistência à normalização da vida modulada pelos psicofármacos. Em nenhum momento se trata de uma apologia do sofrimento, mas, certamente, de uma convivência com o trágico, na qual a arte de escrever está intimamente próxima da sua origem. Isto é, desse ruído inquietante que no fundo da linguagem anuncia, logo que acre um pouco o ouvido, aquilo contra o que se resguarda e ao mesmo tempo a quem nos endereçamos (Foucault, 1963, p. 52).

Heloísa Buarque de Hollanda, crítica literária, ao buscar pistas para prefaciar o então recém-lançado livro Nunca se injete tudo, escrito por Rodrigo Leão, relatava a estranheza de que, mesmo tendo diante de si de um 
jornalista diplomado, poeta e artista este persistia a ser rotulado como esquizofrênico. Partilhamos o estranhamento diante da insígnia "esquizofrenia" atribuída como diagnóstico e que obscurece a densidade poética do artista. Fazemos nossas as palavras de Nietzsche (2000), no seu acerto de contas com a dívida aos antigos, e situamos as questões que o poeta coloca à farmacologização, no terreno impreciso e não diagnosticável do "dizer-sim à vida".

\section{Concluindo provisoriamente}

A partir da analítica do acontecimento farmacologização e dos insumos sobre a obra de Rodrigo Souza Leão como prática de resistência à farmacologização das existências, situamos este texto enquanto emaranhado de linhas e de táticas móveis prestes a formar agenciamentos com outros textos e com outras estratégias estéticas e políticas. A composição de resistências impõe um exercício ético infindo e uma luta política que pode até recuar em algum momento, porém, sem desistência é instado a permanecer nos entremeios e a ocupar espaços, de maneira que, no seu próprio trajeto (mesmo o de aparente recuo), são forjadas as ferramentas de crítica e de rupturas com as práticas instituídas.

As insurgências não cessam de fazer vibrar e de metamorfosear-se como um camaleão que se protege ao se metamorfosear, logrando fugir pelas bordas ao se agenciar de outros modos e a produzir passagens para operar novos planos de composição. Vemos na escrita de Rodrigo Souza Leão, uma prática de liberdade que teve lugar, justamente, por operar no plano da experiência literária que, ao longo do século XX, passou a ser considerado inofensivo e facilmente captável pelas malhas diagnósticas e terapêuticas medicalizantes.
Vale destacar que a literatura se articula a outras modalidades de resistência à farmacologização da vida. Importantes ferramentas de crítica à medicalização vêm sendo organizadas em movimentos sociais e por entidades, com destaque para o Fórum sobre Medicalização da Educação e da Sociedade. Criado em 2010, o fórum articula entidades, acadêmicos, movimentos sociais, grupos de pesquisa, pessoas físicas, usuários, das políticas públicas variadas e de seus familiares, conselhos profissionais, associações e sindicatos. Esse fórum vem realizando debates e também tem participado de audiências públicas, feito pesquisas; organizando seminários e acompanhado a tramitação de projetos de lei municipais, estaduais e nacionais que versam sobre os temas das lutas que estão em jogo; é responsável por publicações, entrevistas e pela difusão de saberes em diversas mídias que mostram como medicalização é um dispositivo vasto, articulado e descontínuo (Souza \& Oliveira, 2013).

Apesar das resistências, e nutrindo-se delas, as forças dos dispositivos de medicalização e farmacologizaçao são recompostas e novos desafios e impasses surgem por meio de contrapoderes. Essa dinâmica requer um movimento ininterrupto de problematização ético, estético e político que opere com alianças e estratégias em um campo tenso e complexo da sociedade atual. Isso passa por uma genealogia das resistências que expõe a fragilidade do dispositivo de farmacologização das existências cada vez mais medicalizadas e, também, pela composição de arquivos de práticas não conformistas de resistência à medicalização das existências. Arquivos urdidos em um trabalho de pesquisa genealógico e capazes de acenar para práticas de liberdade que não estão no exterior da medicalização, mas nas suas dobras, reentrâncias, interstícios. Certamente, a escrita de Rodrigo Souza Leão e a literatura como experiência fazem parte desse arquivo a constituir e cujas fontes estão dispersas. 


\section{Dolores Galindo}

Doutora em Psicologia Social pela Universidade Católica de São Paulo, São Paulo - SP.

Brasil. E-mail: dolorescristinagomesgalindo@gmail.com

\section{Flávia Cristina Silveira Lemos}

Doutora em História Cultural pela Universidade Estadual de São Paulo, São Paulo - SP.

Brasil. E-mail: flaviacslemos@gmail.com

\section{Henrique de Oliveira Lee}

Doutor em Literatura Comparada pela Universidade Federal de Minas Gerais, Belo Horizonte - Brasil. Docente da Universidade Federal do Mato Grosso, Cuiabá - Brasil. E-mail: holiveiralee@gmail.com

\section{Renata Vilela Rodrigues}

Mestranda do Programa de Pós-graduação Estudos de Cultura Contemporânea pela Universidade Federal de Mato Grosso, Cuiabá - Brasil.

\section{Endereço para envio de correspondência:}

Universidade Federal de Mato Grosso, Departamento de Psicologia. Fernando Corrêa da Costa, 2367. Boa Esperança. CEP: 78060900 - Cuiabá, MT - Brasil.

Recebido 26/03/2013, 1a Reformulação: 10/11/2013, Aprovado 12/12/2013. 
Agência de Vigilância Sanitária, Sistema Nacional de Gerenciamento de Produtos Controlados (SNGPC)Anvisa. (2011). Panorama dos Dados do Sistema Nacional de Gerenciamento de Produtos Controlados: um Sistema para o Monitoramento de Medicamentos no Brasil. Boletim de Farmacoepidemiologia da Anvisa, 2(1), 01-09. Recuperado de: http://www.anvisa.gov.br/sngpc/boletins/2011/boletim_sngpc 2edatualizada.pdf.

Bezerra, D. S. (2009). A articulação moebiana entre clínica e a política nos serviços de atenção psicossocial. Psicologia Hospitalar, 7(2), 55-74.

Brzozowski, F. S., \& Caponi, S. (2010). Transtorno de Déficit de Atenção com Hiperatividade: comportamentos anormais, normalização e controle social. In S. Caponi, M. Verdi, F. S. Brzozowski, \& F. Hellmann. Medicalização da vida: Ética, Saúde Pública e Indústria Farmacêutica (pp. 214-228). Palhoça, SC: Ed. Unisul.

Castel, R. (1987). A gestão dos riscos: da antipsiquiatria à pós-psicanálise. Rio de Janeiro: Francisco Alves.

Foucault, M. (1963). Prefácio à Transgressão. In: M. Foucault. Ditos e Escritos, volume III. Rio de Janeiro: Forense Universitária.

Foucault, M. (1970). Loucura, Literatura e Sociedade. In M. Foucault. Problematização do sujeito: psicologia, psiquiatria e psicanálise. Ditos \& Escritos I. (pp. 232-258). Rio de Janeiro: Forense Universitária.

Foucault, M. (1977). Historia de la medicalización. Educación Médica y Salud , 11, 3-25.

Foucault, M. (1978). História da Loucura. São Paulo: Perspectiva.

Foucault, M. (1979). Microfísica do poder. Rio de Janeiro: Graal.

Foucault, M. (1999a). Em defesa da Sociedade: Curso no Collège de France (1975-1976). São Paulo: Martins Fontes.

Foucault, M. (1999b). As palavras e as coisas: uma arqueologia das ciências humanas. São Paulo: Martins Fontes.

Foucault, M. (2002). Os anormais: Curso no Collège de France (1974-1975). São Paulo: Martins Fontes.
Foucault, M. (2004). A ordem do discurso. Aula inaugural no Collège de France, pronunciada em 2 de dezembro de 1970. São Paulo: Loyola.

Foucault, M. (2008). O Nascimento da Biopolítica. Curso no Collège de France (1978-1979). São Paulo: Martins Fontes.

Hollanda, H. B. de. (s.d.). Nunca Injete tudo. Recuperado de: http://www.rodrigodesouzaleao.com.br/files/hor /sobre ele/sobre ele56.htm

Ignácio, V. T. G., \& Nardi, H. C. (2007). A medicalização como estratégia biopolítica: um estudo sobre o consumo de psicofármacos no contexto de um pequeno município do Rio Grande do Sul. Psicologia \& Sociedade, 19(3), 88-95. doi: 10.1590/S010271822007000300013

Leão, R. de S. (2001). Janelas Deitadas (Síndrome). Virtual Books. Recuperado de: http://virtualbooks.terra.com.br/osmelhoresautores/Janelas d eitadas.htm.

Leão, R. de S. (2009). Todos os cachorros são azuis. Rio de Janeiro: 7letras. Recuperado de: http://www.hotsitespetrobras.com.br/cultura/upload/project reading/0 LEITURA todos_os_cachorros.pdf.

Lopes, N. (2004). Medicamentos e percepções do risco. In. Actas dos ateliers do V Congresso Português de Sociologia. Braga, Portugal: Sociedades Contemporâneas: Reflexividade e Ação Atelier.

Lopes, N. M. (2007). Automedicação, saberes e racionalidades leigas em mudança. Revista crítica de ciências sociais, 78, 119-138.

Maciel, M. E. (2008). A enciclopédia de Arthur Bispo do Rosário. In F. Coutinho, M. Carvalho, \& R. Moreira (Orgs.). A vida ao rés-do-chão: artes de Bispo do Rosário (pp. 92-106). Rio de Janeiro: 7 Letras.

Nietzsche, F. (2000). O que devo aos antigos. In F. Nietzsche. Crepúsculo dos Ídolos (ou como filosofar com o martelo) (pp. 98-105). Rio de Janeiro: Relume-Dumará.

Perecy, J., \& Oliveira, L. A. de. (2010). O uso de medicamentos psicotrópicos na contemporaneidade e as formas de subjetivação presentes no imaginário popular referentes à figura do psicólogo. Unoesc \& Ciência - ACHS, 1(2), 183-190. 
Revel, J. (2006). Uma subjetividade que jamais cessa de inventar-se a si própria. Revista do Instituto Humanistas Unisinos, 203, 20-27.

Rose, N. (2007). The Politics of Life Itself. Biomedicine, Power, and Subjectivity in the TwentyFirst Century. Oxford: Princeton University Press.

Staub, M. L., \& Hoch, V. A. (2012). A utilização de psicofármacos no tratamento de saúde mental. Brasília, DF: Secretária do Estado da Educação. Recuperado de http://www.sed.sc.gov.br/secretaria/documentos/doc_download/2332-maria-lucia-staub.
Souza, M. P. R. de, \& Oliveira, F. (2013).“O que dizem os projetos de lei sobre dislexia e transtorno de déficit de atenção e hiperatividade: contribuições da psicologia escolar. In Collares, C. A. L., Moysés, M. A. A. M., Ribeiro, M. C. F. (Orgs.), Novas capturas, antigos diagnósticos na era dos transtornos. (pp. 203-220). São Paulo: Mercado das Letras. 